\title{
Effect of Surface Treatments of Titanium Dioxide Pigments on the Cure of Polyester/Trigylcidyl Isocyanurate Powder Coatings
}

\author{
Stanley Affrossman, Anthony McKee and Richard A. Pethrick, \\ WestCHEM, Department of Pure and Applied Chemistry \\ University of Strathclyde, Thomas Graham Building, \\ 295 Cathedral Street, Glasgow G1 1X1.
}

\begin{abstract}
.
Titanium dioxide pigments will typically have an inorganic surface coating based on a blend of alumina and silica and an organic treatment. Both the organic and inorganic treatments can influence the cure characteristics of polyester powder coatings. This paper attempts to explore the connectivity between the nature of the coating and the cure behaviour of a typical heat cured epoxidised isocyanurate formulation.

It is found that a high silica: alumina content in the inorganic pacification layer significantly retards the cure process, but is influenced by the nature of the organic treatment. The organic surface treatment may accelerate or retard the initial cure process and gelation times. Elemental analysis indicates that certain of the pigments studied have a significantly higher zirconium content and exhibited enhanced cure rates compared with those with the lower zirconium content. This paper illustrates the potential effects of different grades of titanium dioxide on the cure of polyester powder coatings.
\end{abstract}

Keywords, polyester, trigylcidyl isocyanurate, cure data, thermally stimulated current measurements, dynamic mechanical thermal analysis.

\section{Introduction}

Titanium dioxide has photochemical activity and electrochemical activity and in its nano form has finding a range of new applications [1-12]. Pigments however have to be treated to passivate photo and electrical activity and commercial pigments can contain up to $20 \%$ 
of the weight in terms of their surface alumina and silica pacification coating. The nature and quality of the protective coating is know to have an effect on the cure characteristics of certain resin systems $[13,14]$. The nature of the silica /alumina coating which is applied to the $\mathrm{TiO}_{2}$ pigment depends on the type of pigment being created $[15,16]$. $\mathrm{TiO}_{2}$ pigments can be created either via a sulphate or a chloride route [17].

In this paper, we explore the effects of changes in the protective surface coating and the organic treatment on the cure a typical powder coating based on a polyester/trigylcidyl isocyanurate formlation.

The sulphate route produces titanium dioxide after hydrolysis of the sulphate formed by treatment of the ore with sulphuric acid. The titanium dioxide has the anatase form which is converted to the rutile form by calcination. The calcination process involves passing the $\mathrm{TiO}_{2}$ through an oven which has an entry temperature of $350^{\circ} \mathrm{C}$ and an exit temperature of $1000^{\circ} \mathrm{C}$ and the process takes typically $12-16$ hours. The rutile form is created by either prolonged heating at high temperature or by the addition of rutilising catalysts such as zinc or aluminium. Slow cooling is required to achieve a small particle sizes required to generate the desired opacity and scattering characteristics for an efficient pigment.

The chloride route involves the creation of $\mathrm{TiCl}_{4}$ by reaction of the ore with chlorine gas which is in turn converted to the oxide by heating at $1200^{\circ} \mathrm{C}$. $\mathrm{The}^{\mathrm{TiO}}$ is formed in a fine particulate state and has the rutile form.

For both pigments, pacification of the $\mathrm{TiO}_{2}$ particles involves application of a silica /alumina coating. Various small organic molecules may also be added to aid the particle dispersion and enhance the performance of the pigments. The nature of the silica /alumina coatings on $\mathrm{TiO}_{2}$ has been investigated using a variety of surface analytical techniques [15-20]. Examination of a range of $\mathrm{Al}_{2} \mathrm{O}_{3}-\mathrm{SiO}_{2}$ coated $\mathrm{TiO}_{2}$ pigments indicated that $0.2-0.4 \mu \mathrm{m}$ diameter particles are coated to different extents by aluminium and / or silicon oxides and contain varying amounts of hydroxides depending on the method used in the coating process. The extent of the coating influences the measured zeta potential the surface activity and its photochemical activity. Particles size has also been shown to have significant effect on the mechanical properties of the coating

Peer-reviewed, accepted author manuscript of the following article: Affrossman, S., McKee, A, \& Pethrick, R. A. (2015). Effect of surface treatments of titanium dioxide pigments on the cure of polyester/triglycidyl isocyanurate powder coatings. Journal of Coatings Technology Research. 10.1007/s1 1998-015-9697-9 
produced [21]. The pigments used in this study cover the range of compositions typically found in conventional pigments but were especially prepared for the study..

Commercial polyester powder coatings are formulated from a blend of epoxy/polyester, polyester/triglycidyl isocyanurate [TGIC], and polyester /polyurethane [10-12]. In this paper the powder coating is a polyester based on terephthalic and trimellitic acid units combined with neopentyl glycol which is cured with triglycidylisocyanurate. On heating the protected triglycidylisocyanurate groups are activated and react with the available hydroxyl groups forming the polyester. The activation process can be acid/ base catalysed [22-25]. Modaflow, an ethyl acrylate-2-ethylhexyl acrylate copolymer is added to commercial resins to aid dispersion and flow and can influence the cure process.

The study aims to identify the influence of the silica/alumina ration in the pacification coating and possible effects of organic treatments on the cure process aiding the correct selection of the pigment type for a particular application

\section{Experimental}

\section{Materials}

The polyester Uralac P 2400 obtained from DSM, Netherlands. The resin had an acid value of between 27-37 and a glass transition temperature of $63^{\circ} \mathrm{C}$. GPC analysis indicated the following values:- $\mathrm{M}_{\mathrm{n}}-6.32 \times 10^{2}, \mathrm{M}_{\mathrm{w}}-2.33 \times 10^{3}, \mathrm{M}_{\mathrm{z}}-5.01 \times 10^{3}$. the Triglycidyl isocyanurate [TGIC] was supplied by Huntsman UK as was Araldite PT 810 which has an epoxy equivalent of $100-108 \mathrm{~g} / \mathrm{eq}$ and a melting point of $91-95^{\circ} \mathrm{C}$. The aid processing a low molecular weight polyacrylate copolymer of ethyl acetate and 2-hexyl acrylate was added in the form of Modaflow 2000 and has a $\mathrm{M}_{\mathrm{n}}-1.6 \times 10^{4}, \mathrm{M}_{\mathrm{w}}-3.3 \mathrm{x}$ $10^{4}$ and $\mathrm{M}_{\mathrm{z}}-4.9 \times 10^{4}$ and is used as a processing aid.

\section{Titanium dioxide pigments}

The pigments were prepared for the study by Huntsman \{Tioxide\} UK and have the compositions indicated in Table (1). The bulk concentrations are in \% with the exception of the $\mathrm{Fe}, \mathrm{Sn}$ and $\mathrm{Pb}$ which are in ppm. The pigments are treated with various organic compounds which included triethylamine [TEA], trimethylol propane [TMP], trimethylol 
ethane [TME] and low molecular weight polyethylene wax [PE]. For each set of materials, a pigment is included as a baseline reference which does not have any organic surface treatment. The study includes pigments treated with both amine and polyol as these are know to be able to catalyse the epoxy ring opening cure process, but can also potentially interact with the Lewis acid and base sites in the silica and alumina surface coating. A low molecular weight hydrocarbon wax is included in certain types of coatings to aid dispersion in non polar media, such as polyethylene and is also included in this study..

Table (1) Pigment Analysis

\begin{tabular}{|c|c|c|c|c|c|c|c|c|c|c|c|c|c|}
\hline Code & $\mathrm{Al}_{2} \mathrm{O}_{3}$ & $\mathrm{SiO}_{2}$ & $\mathrm{P}_{2} \mathrm{O}_{5}$ & $\mathrm{ZnO}$ & $\mathrm{K}_{2} \mathrm{O}$ & $\mathrm{ZrO}_{2}$ & $\mathrm{SO}_{3}$ & $\mathrm{CaO}$ & $\mathrm{Fe}$ & $\mathrm{Sn}$ & $\mathrm{Pb}$ & $\mathrm{Cl}$ & Organic \\
\hline $1 \mathrm{~A}$ & 3.53 & 0.11 & 0.42 & 0.0015 & 0.021 & 0.60 & 0.07 & 0.024 & 87 & 49 & 63 & 0.003 & None \\
\hline 1B & 3.37 & 0.12 & 0.41 & 0.0015 & 0.021 & 0.58 & 0.08 & 0.023 & 87 & 46 & 54 & 0.007 & TMP \\
\hline $1 \mathrm{C}$ & 3.40 & 0.10 & 0.41 & 0.0016 & 0.020 & 0.59 & 0.07 & 0.023 & 82 & 51 & 58 & 0.002 & TME/PE \\
\hline $1 \mathrm{D}$ & 3.43 & 0.10 & 0.42 & 0.0016 & 0.020 & 0.60 & 0.07 & 0.022 & 86 & 50 & 62 & 0.002 & TME/PE \\
\hline $1 \mathrm{E}$ & 3.38 & 0.11 & 0.41 & 0.0015 & 0.020 & 0.58 & 0.08 & 0.023 & 77 & 63 & 52 & 0.002 & TEA \\
\hline $2 \mathrm{~B}$ & 3.52 & 0.11 & 0.39 & 0.0016 & 0.020 & 0.031 & 0.06 & 0.022 & 85 & 55 & 54 & $<0.001$ & TMP \\
\hline $3 \mathrm{~B}$ & 3.53 & 0.12 & 0.40 & 0.0015 & 0.014 & 0.029 & 0.08 & 0.018 & 94 & 68 & 55 & $<0.001$ & TMO \\
\hline $4 \mathrm{~A}$ & 4.24 & 1.32 & 0.21 & 0.0013 & 0.012 & 0.032 & 0.14 & 0.016 & 75 & 49 & 49 & 0.001 & None \\
\hline 4B & 4.40 & 0.10 & 0.23 & 0.0016 & 0.015 & 0.024 & 0.13 & 0.020 & 0.01 & 47 & 59 & 0.001 & $\mathrm{TMP} / \mathrm{PE}$ \\
\hline $4 \mathrm{C}$ & 4.36 & 0.10 & 0.23 & 0.0016 & 0.014 & 0.025 & 0.13 & 0.021 & 86 & 68 & 59 & 0.001 & $\mathrm{TME} / \mathrm{PE}$ \\
\hline 4D & 4.23 & 0.10 & 0.22 & 0.0015 & 0.014 & 0.027 & 0.12 & 0.021 & 84 & 57 & 55 & 0.001 & TME/PE \\
\hline $4 \mathrm{E}$ & 4.29 & 0.09 & 0.23 & 0.0014 & 0.014 & 0.028 & 0.11 & 0.020 & 80 & 68 & 57 & $<0.001$ & TEA \\
\hline $5 \mathrm{~A}$ & 0.61 & 4.00 & 0.16 & 0.0015 & 0.056 & 0.024 & 0.05 & 0.025 & 0.01 & 57 & 58 & $<0.001$ & None \\
\hline $5 \mathrm{~B}$ & 0.61 & 4.00 & 0.16 & 0.0015 & 0.056 & 0.025 & 0.04 & 0.024 & 0.01 & 68 & 57 & $<0.001$ & TMP \\
\hline $5 \mathrm{C}$ & 0.59 & 3.94 & 0.16 & 0.0016 & 0.056 & 0.025 & 0.04 & 0.024 & 94 & 53 & 53 & $<0.001$ & PE/TME+TMP \\
\hline $5 \mathrm{D}$ & 0.60 & 3.99 & 0.16 & 0.0015 & 0.057 & 0.024 & 0.04 & 0.023 & 92 & 58 & 55 & $<0.001$ & $\mathrm{PE} / \mathrm{TME}$ \\
\hline $5 \mathrm{E}$ & 0.67 & 4.05 & 0.17 & 0.0015 & 0.058 & 0.026 & 0.05 & 0.024 & 0.01 & 63 & 57 & 0.002 & TEA \\
\hline $6 \mathrm{~A}$ & 2.43 & 2.03 & 0.23 & 0.0015 & 0.043 & 0.025 & 0.18 & 0.019 & 87 & 71 & 57 & $<0.001$ & None \\
\hline $6 \mathrm{~B}$ & 2.39 & 1.96 & 0.23 & 0.0015 & 0.043 & 0.024 & 0.16 & 0.021 & 0.01 & 63 & 52 & $<0.001$ & TMP \\
\hline $6 \mathrm{C}$ & 2.37 & 1.92 & 0.23 & 0.0015 & 0.043 & 0.024 & 0.17 & 0.019 & 84 & 62 & 59 & $<0.001$ & PE/TME+TMP \\
\hline $6 \mathrm{D}$ & 2.35 & 1.94 & 0.23 & 0.0015 & 0.042 & 0.024 & 0.16 & 0.020 & 87 & 60 & 58 & $<0.001$ & PE/TME \\
\hline $6 \mathrm{E}$ & 2.37 & 1.93 & 0.23 & 0.0014 & 0.042 & 0.026 & 0.16 & 0.019 & 85 & 50 & 53 & $<0.001$ & TEA \\
\hline
\end{tabular}


Concentrations in \% with the exception of $\mathrm{FE}, \mathrm{Sn}, \mathrm{Pb}$ which are in ppm.

\section{Surface area measurements}

The surface area is important in defining the extent to which a pigment is capable of absorbing resin in the initial stages of cure and nitrogen adsorption isotherms were measured using a Micromertics Accusorb 2100E vacuum system for each pigment. Each sample was weighed accurately into a clean glass sample holder and then connected to the vacuum system. The sample was allowed to out-gas overnight at a temperature of $180^{\circ} \mathrm{C}$ under a pressure of $0,15 \mathrm{~mm} \mathrm{Hg}$. Once the sample had been fully out gassed it was cooled to $77 \mathrm{~K}$ and its nitrogen adsorption isotherm was measured. For surface area measurements the nitrogen isotherm was measured for relative pressures between 0.05 and 0.35 whereas to determine porosity the complete isotherm was measured.

The BET surface areas of all the pigments used were measured and the typical accuracy was $\pm 0.5 \mathrm{~m}^{2} \mathrm{~g}^{-1}$, table (2). t-Plots were also constructed for the pigments, using the procedure proposed by de Boer et. al. [26]. All pigments exhibited reversible Type II isotherms characteristic of non porous or macroporous surfaces. All the t-plots had the same shape at low relative pressures. The t-plots were linear and passed through the origin indicating unhindered multilayer adsorption is taking place on all parts of the surface. At high relative pressure the slope deceases which has been interpreted as being due to areas of surface being blocked for further adsorption. The adsorption data indicates that there is no capillary condensation occurring and that the pigments all have surface areas in the range $10-23 \mathrm{~m}^{2} \mathrm{~g}^{-1}$. The differences arise primarily as a consequence of differences in the nature of the silica/alumina coating.

Table (2) Surface areas of pigments calculated using the BET equation.

\begin{tabular}{|c|c|c|c|c|c|c|c|}
\hline Code & Area $\left(\mathrm{m}^{2} \mathrm{~g}^{-1}\right)$ & Code & Area $\left(\mathrm{m}^{2} \mathrm{~g}^{-1}\right)$ & Code & Area $\left(\mathrm{m}^{2} \mathrm{~g}^{-1}\right)$ & Code & Area $\left(\mathrm{m}^{2} \mathrm{~g}^{-1}\right)$ \\
\hline 1A & 13 & 1B & 16 & 1C & 15 & 1D & 15 \\
\hline 1E & 15 & 2B & 16 & 3B & 17 & 4A & 15 \\
\hline 4B & 20 & 4C & 19 & 4D & 18 & 4E & 19 \\
\hline 5A & 23 & 5B & 22 & 5C & 21 & 5D & 20 \\
\hline
\end{tabular}




\begin{tabular}{|c|c|c|c|c|c|c|c|}
\hline $5 \mathrm{E}$ & 18 & $6 \mathrm{~A}$ & 11 & $6 \mathrm{~B}$ & 12 & $6 \mathrm{C}$ & 11 \\
\hline $6 \mathrm{D}$ & 12 & $6 \mathrm{E}$ & 10 & & & & \\
\hline
\end{tabular}

\section{Powder coating production}

The pigment was blended with $10 \%$ Modaflow in a water cooled Henshel mixer for ten minutes. The composition of the blends used are summarised in table (3). The pigment was compounded with the polyester in a twin screw extruder operating at $100^{\circ} \mathrm{C}$ and rapidly cooled on a water cooled bench. The extrudate was then granulated using a pin disc mill and classified so that the final powder passed through a $50 \mu \mathrm{m}$ sieve. This resin powder was then converted into pigment by the addition of TGIC and tioxide pigment.

The formulations used were created on a $2 \mathrm{~kg}$ batch scale and contained; $1029.8 \mathrm{~g}$ polyester resin, 86.9g, TGIC, $138.5 \mathrm{~g}$, Modaflow, and $744.5 \mathrm{~g}$ pigment and for the unpigmented powder; $1637.4 \mathrm{~g}$ polyester resin, 138.2g TGIC, 220.2g Modaflow. In both cases, the Modaflow is at a level of $1 \%$ with respect to the resin and the resin to TGIC ratio is 93:7. Formulations were also created to explore the effects of variations in the Modaflow to total resin ratio. In addition, certain other formulations were created in which the above ratios were changed, table (3). In all cases the pigment loading is $64.5 \%$ with respect to the resin. Many of the formulations were prepared in duplicate and certain in triplicate to check the consistency of the process. The pigments used for the nonstandard coatings were $4 \mathrm{~B}$ and $6 \mathrm{~B}$. The powder coating was stored in air tight jars until required for analysis and testing.

\section{Strathclyde curometer}

The cure characteristics of the powders were obtained using the Strathclyde curometer $[27,28]$ The curometer uses a vibrating probe to sense the change in the viscosity of the material and has been shown previously to be ideally suited for the study of filled polymer systems [29]. The instrument was operated at a frequency of $2 \mathrm{~Hz}$. The sample of powder $(7.77 \mathrm{~g})$ was placed in a $2 \mathrm{~cm}$ diameter glass container which was heated with an oil bath. All the measurements were carried out at $210^{\circ} \mathrm{C}$. The temperature of the sample was monitored with a digital thermometer. A typical plot is shown in figure (1). The amplitude and out of phase signal were used to calculate the viscosity profile. Using 
the theory presented previously [26], the viscosity time profile was calculated. A viscosity of $10^{4} \mathrm{Pas}$ was taken as indicating gelation of the material.

Table (3) Formulation of the powder coatings

\begin{tabular}{|c|c|c|c|c|c|c|}
\hline Code (pigment) & Pigment (g) & $\operatorname{Resin}(\mathrm{g})$ & Resin/Modaflow (g) & TGIC (g) & Pigment $\%$ & Modaflow \% \\
\hline 1 & & 1357.9 & 37.4 & 104.8 & 0 & 0.25 \\
\hline $2(4 b \& 6 b)$ & 558.6 & 844.9 & 23.25 & 65.2 & 64.5 & 0.25 \\
\hline 3 & & 1320.9 & 74.7 & 104.5 & 0 & 0.5 \\
\hline $4(4 b \& 6 b)$ & 558.6 & 823.9 & 46.6 & 65.2 & 64.5 & 0.5 \\
\hline 5 & & 1102.9 & 294.1 & 103.0 & 0 & 2.0 \\
\hline $6(4 b \& 6 b)$ & 558.6 & 698.2 & 186.2 & 65.2 & 64.5 & 2.0 \\
\hline 7 & & 822.1 & 576.9 & 101.0 & 64.5 & 4.0 \\
\hline $8(4 b \& 6 b)$ & 558.6 & 530.7 & 372.4 & 65.2 & 64.5 & 4.0 \\
\hline $9(4 b)$ & 40.0 & 1604.8 & 219.5 & 135.7 & 2 & 1 \\
\hline $10(4 b)$ & 180.0 & 1490.2 & 203.8 & 126.0 & 11 & 1 \\
\hline $11(4 b)$ & 360.0 & 1342.8 & 183.7 & 113.6 & 24 & 1 \\
\hline $12(4 b)$ & 744.5 & 1029.8 & 138.5 & 86.0 & 64 & 1 \\
\hline $13(4 b)$ & 900.0 & 900.7 & 123.2 & 76.1 & 89 & 1 \\
\hline $14(4 b)$ & 1100.0 & 736.9 & 100.8 & 62.3 & 133 & 1 \\
\hline $15(4 b \& 6 b)$ & 1369.9 & 27.9 & 0 & 102.7 & 2 & 0 \\
\hline $16(4 b \& 6 b)$ & 1195.2 & 215.1 & 0 & 89.6 & 18 & 0 \\
\hline $17(4 b \& 6 b)$ & 1038.1 & 384.1 & 0 & 77.9 & 37 & 0 \\
\hline $18(4 b \& 6 b)$ & 923.1 & 507.7 & 0 & 69.2 & 55 & 0 \\
\hline $19(4 b \& 6 b)$ & 1021.8 & 26.4 & 352.7 & 99.1 & 2 & 4 \\
\hline $20(4 b \& 6 b)$ & 895.9 & 208.3 & 308.7 & 86.9 & 18 & 4 \\
\hline $21(4 b \& 6 b)$ & 373.7 & 781.2 & 269.3 & 75.8 & 37 & 4 \\
\hline $22(4 b \& 6 b)$ & 495.5 & 696.9 & 240.0 & 67.6 & 55 & 4 \\
\hline $23(6 b)$ & 90.7 & 1280.3 & 90.7 & 101.8 & 2 & 1 \\
\hline $24(6 b)$ & 79.3 & 1118.4 & 79.3 & 88.9 & 18 & 1 \\
\hline $25(6 b)$ & 68.7 & 972.5 & 68.7 & 77.3 & 37 & 1 \\
\hline $26(6 b)$ & 61.3 & 865.3 & 61.3 & 68.8 & 55 & 1 \\
\hline $27(6 b)$ & 20.0 & 1175.9 & 20.0 & 89.5 & 18 & 0.25 \\
\hline $28(6 b)$ & 40.0 & 1156.5 & 40.0 & 89.3 & 18 & 0.5 \\
\hline $29(6 b)$ & 156.7 & 1043.3 & 156.7 & 88.2 & 18 & 2 \\
\hline 30 & & 1387.5 & & 112.5 & 0 & 0 \\
\hline
\end{tabular}




\section{Thermally Stimulated Discharge Measurements}

The method has been described previously $(29,30)$ and allows identification of the glass transition temperature, $\mathrm{T}_{\mathrm{g}}$ and space charging effects which are important in the case of powder coatings. Approximately $5 \mathrm{~g}$ of powder was pressed into the form of a disc between smooth Teflon discs using a Spacec stainless steel die press of $3 \mathrm{~cm}$ diameter. An Apex hydraulic press Type 340-4 was used to apply a pressure of $3000 \mathrm{kgm}^{-2}$ and was maintained at an appropriate temperature either to achieve consolidation or cure. Cure schedules was typically 28 minutes at $200^{\circ} \mathrm{C}$. Poling of the sample was achieved by heating to the poling temperature $T_{p}$ with a field of $5 \mathrm{kVcm}^{-1}$ applied for a period of 10 minutes. The sample was then cooled to $0^{\circ} \mathrm{C}$ and the field removed by shorting the two electrodes. The discharge which is associated with the release of trapped charges was then measured using a Keighley $610 \mathrm{C}$ electrometer and the sample heated at a rate of $3^{0} \mathrm{C}$ $\min ^{-1}$ under a nitrogen atmosphere. Traces were obtained over the temperature range from $298-473 \mathrm{~K}$.

\section{Dynamic Mechanical Thermal Analysis}

A Rheometrics Dynamic Mechanical Thermal Analyser (DMTA) was used in three point bending mode and operated over a temperature range -180 to $+300^{\circ} \mathrm{C}$ and frequency range 0.01 to $200 \mathrm{~Hz}$. The samples studied were $\sim 1 \mathrm{~mm}$ thick and produced by curing an appropriate amount of powder in a PTFE coated mould. Measurements were made at a frequency of $1 \mathrm{~Hz}$. The output data were the bending modulus E' and $\tan \delta$.

\section{Results and Discussion}

\section{Curometer Measurements}

It has been reported previously, changing the nature of the surface treatment of the pigment influences the rate of cure of powder coatings [11,13,14]. In this study we explore the effects of change of the surface coating and possible effects of Modaflow on the nature of the cure process. 
A typical curometer traces for the polyester/TGIC powder coating is shown in figure (1). The initial amplitude of the probe motion is large, the probe moving freely through the free flowing powder, figure (1A).

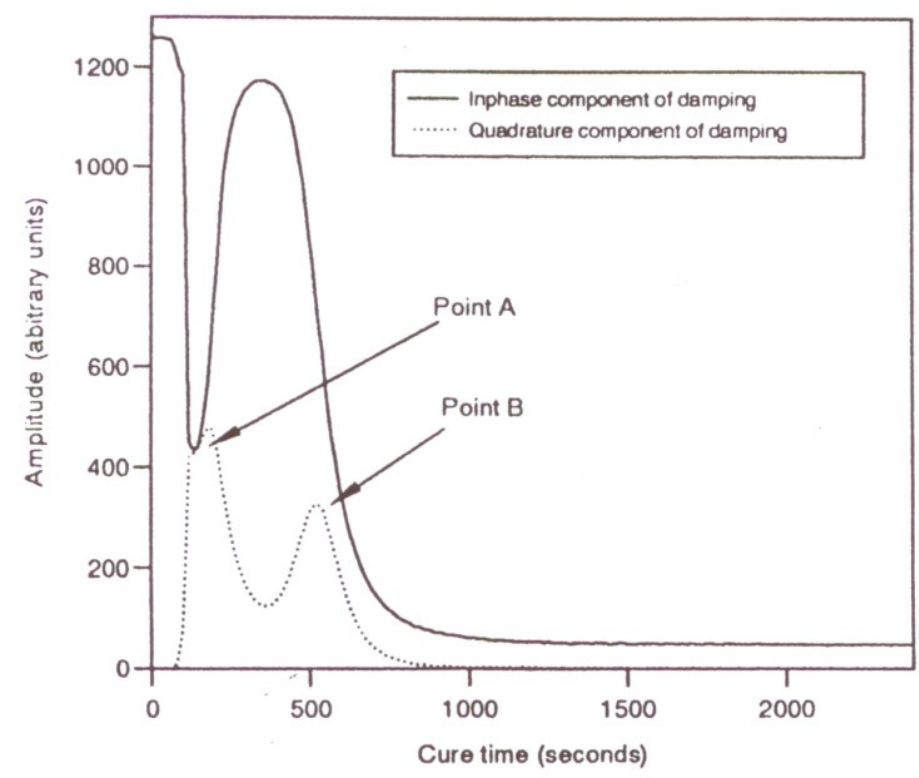

[A]

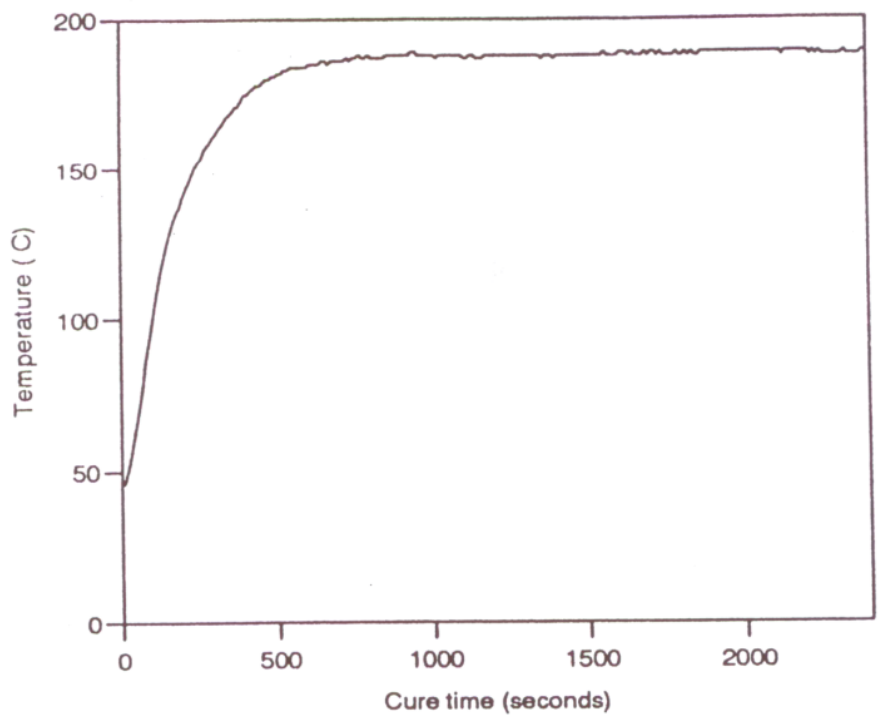

[B]

Figure (1) Typical cure curves for a polyester/TGIC powder coating; amplitude and phase plots for the curing resin, [A] and heating profile for the resin system [B] 
As the powder melts its wets the probe and initially forms a viscous liquid layer. Further heating of the melt, lowers the viscosity and the amplitude of the motion of the probe increases. The initial drop in amplitude is a reflection of the melting and wetting process for the probe. Once the powder has melted activation of the TGIC can start to occur and cure of the resin is initiated. The start of the cure process can be designated by the point A, which corresponds to the formation of the molten resin mixture. The initial change in amplitude reflects the change in the viscosity. The initial decrease in the amplitude is proportional to the increase in the increase in the viscosity. As the cure proceeds then viscosity becomes complex and the quadurature signal rises as the fluid takes on viscoelastic characteristics. The temperature of the powder is rising as indicated in figure (1B) and the cure temperature is reached after about 500 seconds. At this time the powder has become fairly fluid and the amplitude of the motion of the probe has risen to almost the value which it had when immersed in the original powder and the quadurature has dropped indicating the fluid is less viscous. As cure proceeds the amplitude falls and eventually when cure is completed the amplitude becomes constant and reflect the fact that the coating is now in a rubbery state.

The gelation of the coating is reflected in the quadurature having a maximum value, designated point $\mathrm{B}$, whereas vitrification corresponds to the point at which the amplitude has reached a small but constant value. The accuracy of the method for the characterisation of the cure times was checked by performing six measurements on the unpigmented coatings. The average gelation time was found to be $828 \pm 15$ seconds. The time between point A and point B was designated the 'initial cure time' and values of 434 \pm 17 seconds were observed. The main sources of errors in the measurement were attributed to variability of the thermal contact between the sample and the metal heating block and differences in the depth to which the probe was immersed in the powder coating.

\section{Effects of organic surface treatment of the pigment on the cure behaviour.}

Organic treatments are used to assist the dispersion of the pigment in the matrix. The compounds which are used depend on the surface activity of the silica/alumina coating and are typically are triethylamine [TEA], trimethylol propane [TMP], trimethylol ethane

Peer-reviewed, accepted author manuscript of the following article: Affrossman, S., McKee, A. \& Pethrick, R. A. (2015). Effect of surface treatments of titanium dioxide pigments on the cure of polyester/triglycidyl isocyanurate powder coatings. Journal of Coatings Technology Research. 10.1007/s11998-015-9697-9 
[TME] and low molecular weight polyethylene wax [PE]. These compounds have both the ability to interact with acid and basic sites or be adsorbed on the pigment surface and influence the TGIC reaction. The organics are added to the slurry after the deposition of the silica:alumina coating and the excess is removed in the drying process. Low levels of these molecules will be adsorbed on the surface of the coating depending on the nature of the sites present.

The ST $(\mathrm{x})$ coded pigments were prepared with and without the addition of any organic treatment but with varying silica:alumina ratios in the coatings. The cure characteristics are presented in Table (4), the initial cure time is designated by A in figure (1) and corresponds to the point at which the viscosity starts to increase whereas point $\mathrm{B}$ is designated as the gelation time. In certain of the formulations, the cure was inhibited and this point could not be precisely determined. Comparison of the cure times for the pigment which had not been treated with an organic coating, table (4) are $1 \mathrm{~A}(\mathrm{Si}-0.11)$ (390s), 4A ( $\mathrm{Si}-1.32)(360 \mathrm{~s}), 5 \mathrm{~A}(\mathrm{Si}-4.00)(460 \mathrm{~s})$ and $6 \mathrm{~A}(\mathrm{Si}-2.03)(600 \mathrm{~s})$ shows an initial drop to 600 s at $2.03 \%$ and then a decrease with increasing $\mathrm{SiO}_{2}$ content in the coating. The gelation times for $1 \mathrm{~A}(1010 \mathrm{~s}), 4 \mathrm{~A}(1300 \mathrm{~s})$ and 5A (1760s) show a progressive increase as the silica:alumina ratio is increased. The pigment $6 \mathrm{~A}$ which contains equal amounts of silica and alumina did not show a clear gelation time.

Table 4 Gelation times for various formulations.

\begin{tabular}{|l|l|l|l|l|l|}
\hline $\begin{array}{l}\text { Code } \\
\text { (pigment) }\end{array}$ & $\begin{array}{l}\text { Initial cure } \\
\text { time (secs) }\end{array}$ & $\begin{array}{l}\text { Gelation } \\
\text { time (secs) }\end{array}$ & Code & $\begin{array}{l}\text { Initial cure } \\
\text { time (secs) }\end{array}$ & $\begin{array}{l}\text { Gelation } \\
\text { time (secs) }\end{array}$ \\
\hline ST1(neat) & 390 & 820 & ST2 (1A) & 430 & 1010 \\
\hline ST3 (1B) & 370 & 1080 & ST4 (1C) & 380 & 1070 \\
\hline ST5 (1D) & 340 & 910 & ST6 (1E) & 370 & 890 \\
\hline ST7 (2B) & 260 & 710 & ST8 (3B) & 360 & 1130 \\
\hline ST9 (4A) & 360 & 1300 & ST10 (4B) & 390 & 1160 \\
\hline ST11 (4C) & 360 & 1070 & ST12 (4D) & 340 & 1010 \\
\hline ST13 (4E) & 270 & 720 & ST14 (5A) & 460 & 1760 \\
\hline ST15 (5B) & 470 & - & ST16 (5C) & 470 & - \\
\hline
\end{tabular}




\begin{tabular}{|l|l|l|l|l|l|}
\hline ST17 (5D) & 400 & 1290 & ST18 (5E) & 330 & 790 \\
\hline ST19 (6A) & 600 & - & ST20 (6B) & 560 & 2020 \\
\hline ST21 (6C) & 570 & 1840 & ST22 (6D) & 550 & - \\
\hline ST23 (6E) & 390 & 1050 & & & \\
\hline
\end{tabular}

Changing the silica:alumina ratio, which will alter the acid-base nature of surface of the pigment, and appears to inhibit the cure process, implying that the pigment surface is interacting with the curing resin system.

\section{Trimethyol propane [TMP]}

Comparison of the initial cure time data for $1 \mathrm{~B}\left(\mathrm{Al}_{2} 0: \mathrm{Si}_{2} ; 3.53: 0.11\right)$ (370s), $2 \mathrm{~B}$ $\left(\mathrm{Al}_{2} 0: \mathrm{Si}_{2} ; 3.53: 0.11\right)(260 \mathrm{~s})$, shows a decrease in the initial cure time for essentially the same level of alumina and silica in the coating and the only difference between the pigments is the zirconium level in the pigment. Zirconium may be present as either the oxide $\mathrm{ZrO}_{2}$ or as the sulphate and its presence appears to accelerate the cure, . Increasing the silica level $5 \mathrm{~B}\left(\mathrm{Al}_{2} 0: \mathrm{Si}_{2} ; 0.61: 4.00\right)(470 \mathrm{~s})$ increases the initial cure time indicating a less efficient initiation process and it was difficult to determine the gelation time. Pigment 6B ( $\left.\mathrm{Al}_{2} 0: \mathrm{Si}_{2} ; 2.39: 1.96\right)$ (560s) has a lower level $\mathrm{Zr}(0.024)$ and a higher level of $\mathrm{SiO}_{2}$ and shows the expected retardation of the initial cure with increase in silica level. The gelation times for the pigments; 1B (1080s), 2B (710s) follow the trend in the initial cure times and indicate that the zirconium appears to be catalysing the cure whereas $4 \mathrm{~B}$ $(1160 \mathrm{~s})$ and $6 \mathrm{~B}(2020 \mathrm{~s})$ show that increasing the $\mathrm{SiO}_{2}$ is retarding the cure. This observation implies that the zirconium may be segregating to the surface to some extent, however we were not able to prove this.

An alternative explanation for the fast cure in the case of $2 \mathrm{~B}$ could be the effects of the TMP, however since this is present in all the B series pigments it is difficult to explain why it should only have an effect in pigment $\mathrm{B}$, which is curing faster than the neat resin.

\section{Triethylamine [TEA]}

Triethylamine introduces into the resin the possibility of creating a quaternary amine which could catalyse the activation process for the TGIC. Comparison of the initial cure

Peer-reviewed, accepted author manuscript of the following article: Affrossman, S., McKee, A. \& Pethrick, R. A. (2015). Effect of surface treatments of titanium dioxide pigments on the cure of polyester/triglycidyl isocyanurate powder coatings. Journal of Coatings Technology Research. 10.1007/s1 1998-015-9697-9 
data for $1 \mathrm{E}\left(\mathrm{Al}_{2} 0: \mathrm{Si}_{2} ; 3.38: 0.11\right)(370 \mathrm{~s})$, with $4 \mathrm{E}\left(\mathrm{Al}_{2} 0: \mathrm{Si}_{2} ; 4.29: 0.09\right)(270 \mathrm{~s})$ shows a dreaces in the initial cure time with increased alumina content, however $5 \mathrm{E}\left(\mathrm{Al}_{2} \mathrm{O}: \mathrm{Si}_{2}\right.$; $0.67: 4.05)(330 \mathrm{~s})$ and $6 \mathrm{E}\left(\mathrm{Al}_{2} 0: \mathrm{Si}_{2}: 2.37: 1.93\right)(390 \mathrm{~s})$ shows a more complex change with silica content and pigments $4 \mathrm{~A}\left(\mathrm{Al}_{2} 0: \mathrm{Si}_{2}: 4.24: 1.32\right)(360 \mathrm{~s})$ and $5 \mathrm{E}\left(\mathrm{Al}_{2} 0: \mathrm{Si}_{2}\right.$ : $0.61: 4.05)(330 \mathrm{~s})$ are showing cure behaviour which is faster than that of the pure resin. This implies that the TEA may be having a catalytic effect on the initial stages of TGIC activation. The gelation times: 1E( 890s), 4E (720s), 5E (790s) and 6E (1050s) show cure times which are faster than those of the pure resin for low silica levels but become slower for the higher silica levels, when the zirconium level is low. The data once more indicate that the zirconium is influencing the cure process, presumably by changing the surface chemistry but we must also consider the catalytic effect of the TEA on the epoxy cure process.

\section{Trimethyol propane [TMP] / polyethylene wax.}

The addition the PE wax will not be expected to catalyses the reaction, but could block some of the active surface sites on the pigment. Comparison of the initial cure data for $1 \mathrm{C}$ (380s) 1D (380s), 4B (390s), and 4C (360s) indicates the addition of the wax has eliminated the effect of the surface seen with TMP alone and this trend is reflected in the gelation times; 1C (1070s), 1D (910s), 4B (1160s) and 4C (1070s) which are similar with the exception of $1 \mathrm{D}$ which is slightly faster.

\section{Modaflow effects on cure}

In commercial formulations, small amounts of flow control agents, such as Modaflow are added to avoid problems such as 'orange peel and pin hole formation. The Modaflow which is an ethyl acrylate-2-ethylhexyl acrylate copolymer has the potential of interacting with the pigment surface and blocking certain surface sites. The effect of varying levels of Modaflow addition between 0 and $4 \%$ on the cure process, for unpigmented and two pigmented resins, 4B and 6B were investigated, figure (2).

The dominant effect is the nature of the pigment; $4 \mathrm{~B}\left(\mathrm{Al}_{2} \mathrm{O}: \mathrm{SiO}_{2} ; 4.400 .1\right)$ showing comparable rates of cure to the unpigmented resin, whereas $6 \mathrm{~B}\left(\mathrm{Al}_{2} \mathrm{O}: \mathrm{SiO}_{2} ; 2.39: 1.96\right)$ is inhibited both in the initial time for cure and gelation. 
Addition of a low level of Modaflow to the resin reduces the initial cure time but further addition increases the initial cure time, figure (2). High levels $\sim 4 \%$ of Modaflow produce a reduction in the initial cure time and there is no evidence of blocking of surface sites as seen in the case of the wax addition. Both pigments were treated with TMP and the changes in the cure characteristics appear attributable to changes in the $\mathrm{SiO}_{2}$ level from $0.12 \%$ in $4 \mathrm{~A}$ to 1.96 in $6 \mathrm{~B}$. The addition of between 0.5 and $1 \%$ of Modaflow causes an increase in the gel times for the 4B pigment which has the highest level of $\mathrm{SiO}_{2}$, whereas $4 \mathrm{~B}$, which is the pigment with the highest level of $\mathrm{Al}_{2} \mathrm{O}_{3}$ shows an initial cure time which is faster than the pure resin.

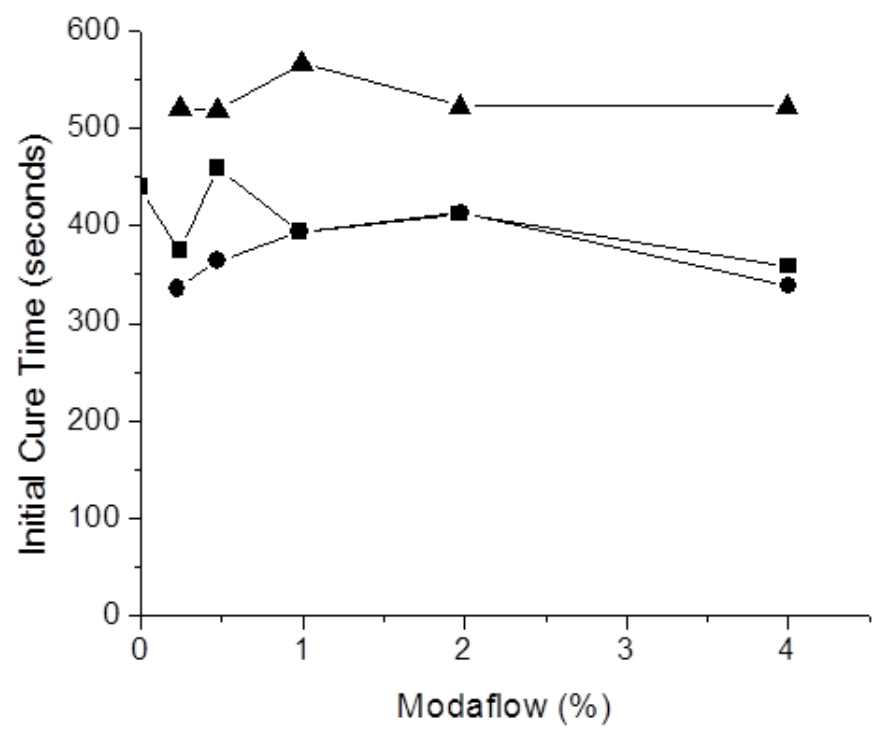

[A] 


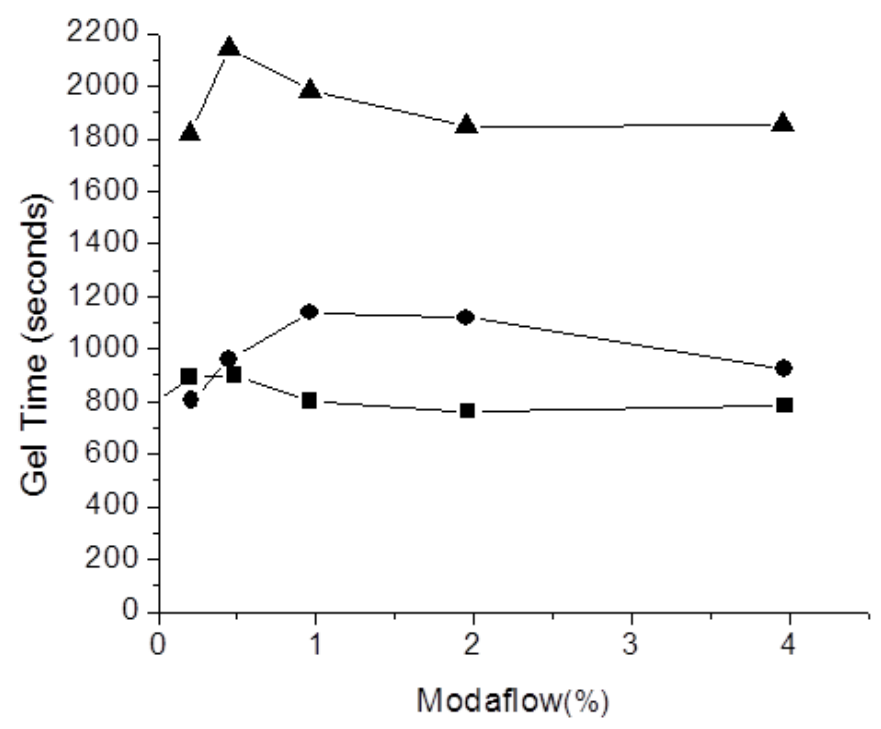

[B]

Figure (2) Initial Cure Time [A] and Gelation Time [B] as a function of Modaflow level. Key:- - - unpigmented, - - pigment 4B at 64\% loading, $\boldsymbol{\Delta}$ - pigmented $6 \mathrm{~B}$ at $64 \%$ loading. Error bars are the size of the data points

\section{Effect of pigment loading in a Modaflow free coating}

To explore any interactions caused by the presence of Modaflow, the effects of varying the level of pigments $4 \mathrm{~B}$ and $6 \mathrm{~B}$ were investigated, figure (3). These coatings do not contain Modaflow and therefore reflect the interaction of the polyester/TGIC with the pigment. At low levels of pigment addition, $<15 \%$, there is little effect, however at higher loadings the inhibition effects of 4B become evident both in the initials stages of cure and in the gelation time. The pigment $6 \mathrm{~B}$ shows a slight decrease in its initial cure time at very high loadings but there is a small increase in the gelation time. Since in the pigmented coating there is less monomer to convert to polymer the observation of these increases implies significant inhibition of the polymerization process. The level of loading is clearly not the controlling factors, but the level of silica in the coating has a dramatic effect on the cure process. 


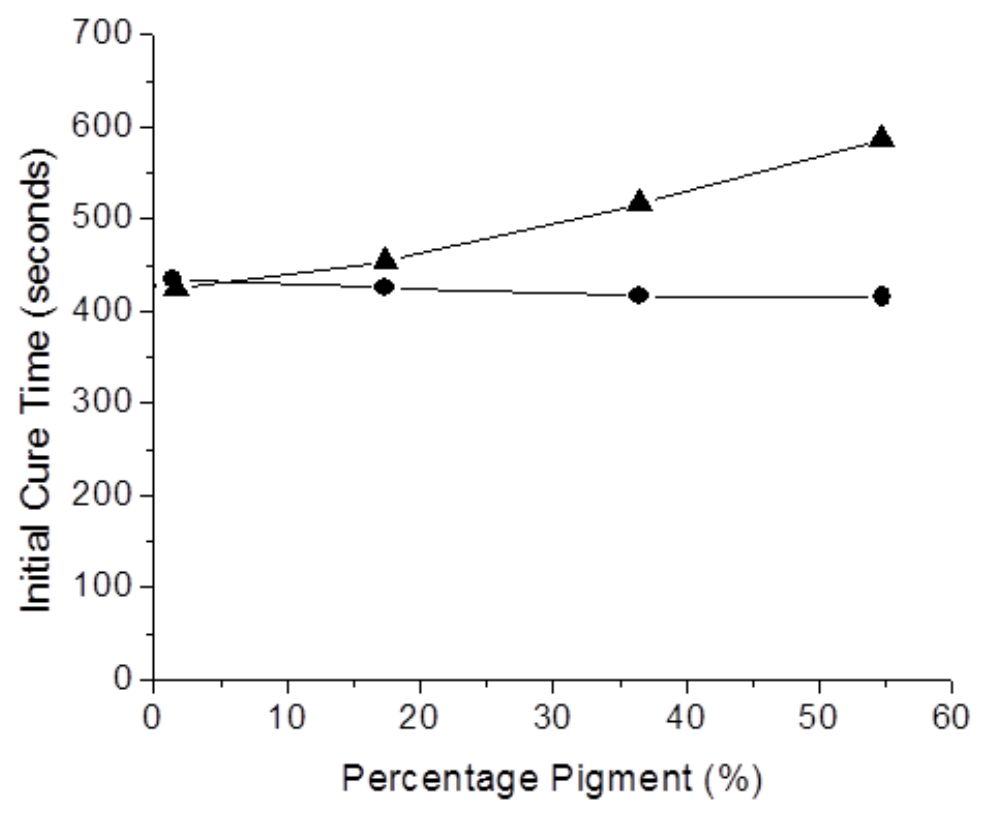

[A]

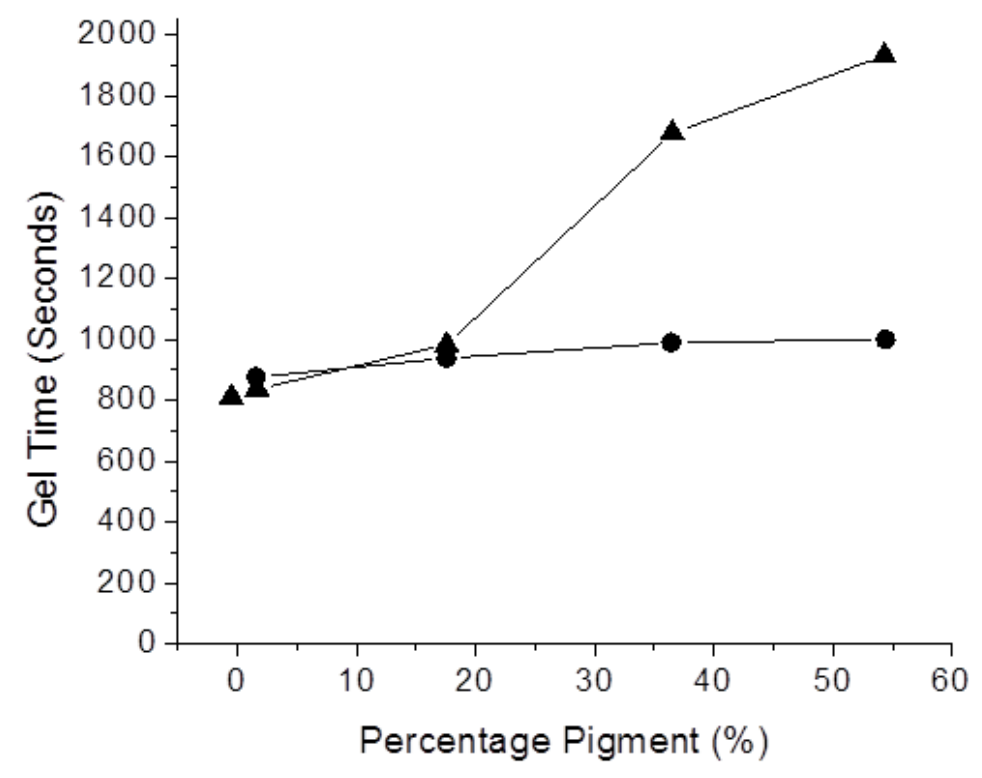

[B]

Figure (3) Effect of Pigment loading of Modoflow free coatings. Key:- - - unpigmented, - - pigment 4B, $\boldsymbol{\Lambda}$ - pigmented 6B. Error bars are the size of the data points

\section{Effect of pigment loading with $1 \%$ Modaflow being present}


A series of experiments were performed on coatings prepared with 1\% of Modaflow in the coating, figure (4). Whereas in the unpigmented coatings the cure process appears to be unaffected by low levels of pigment addition, when Modaflow is present there is a significant reduction in the initial cure time for $4 \mathrm{~B}$ whereas $6 \mathrm{~B}$ exhibits behaviour which is similar to the coating which does not contain Modaflow. The reduction in the initial cure time with $4 \mathrm{~B}$ may be attributed to the effect of Modaflow assisting the viscosity reduction and promoting the activation process. As with coatings which did not contain Modaflow, pigment 6B shows a more significant effect on both the initial stages of cure and on gelation times than 4B. The difference in observed behaviour reflects the changes in the silica: alumina ratio in the pigments surface coating.

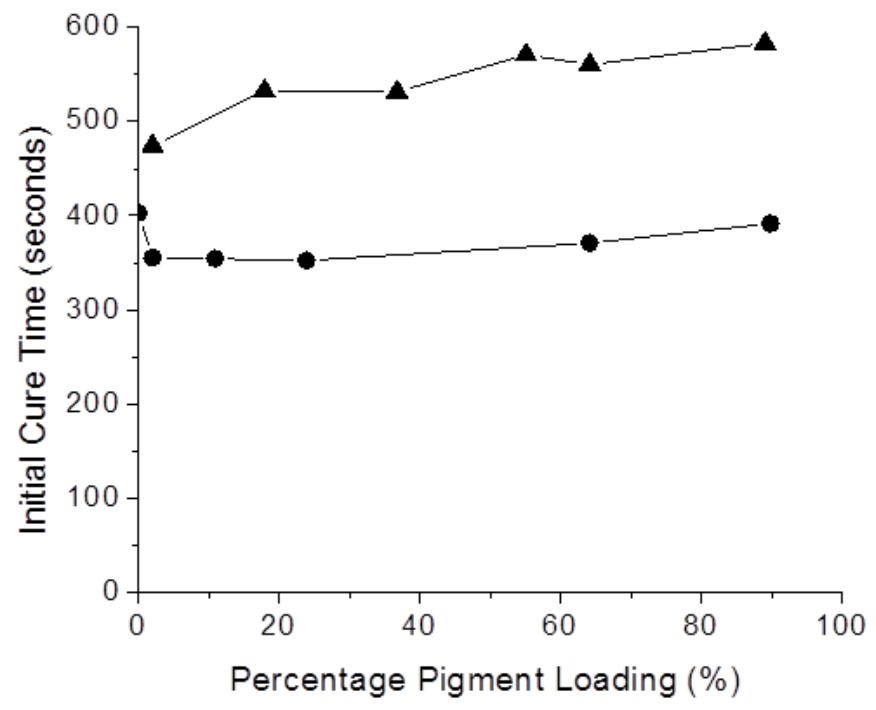

[A] 


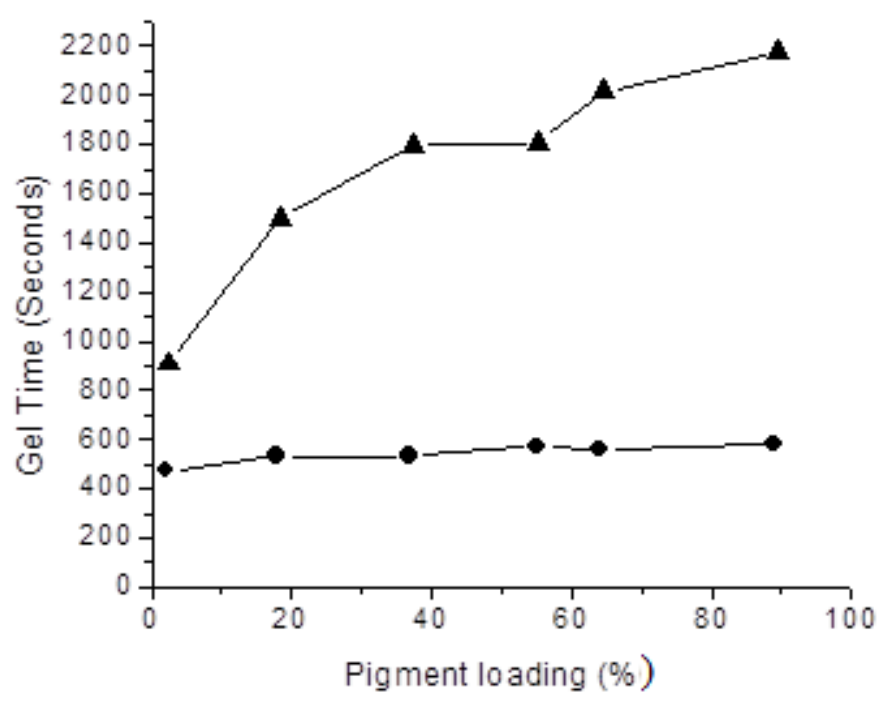

[B]

Figure (4) Effect of pigment loading on Initial Cure Time[A] and Gelation Time [B] with 1\% Modaflow. Key:- $\bullet$ - pigment 4B, $\boldsymbol{\Delta}$ - pigment 6B. Error bars are the size of the data points

\section{Effect of pigment loading with $4 \%$ Modaflow being present}

Coatings containing 4B and 6B with a 4\% Modaflow level were studied, figure (5).

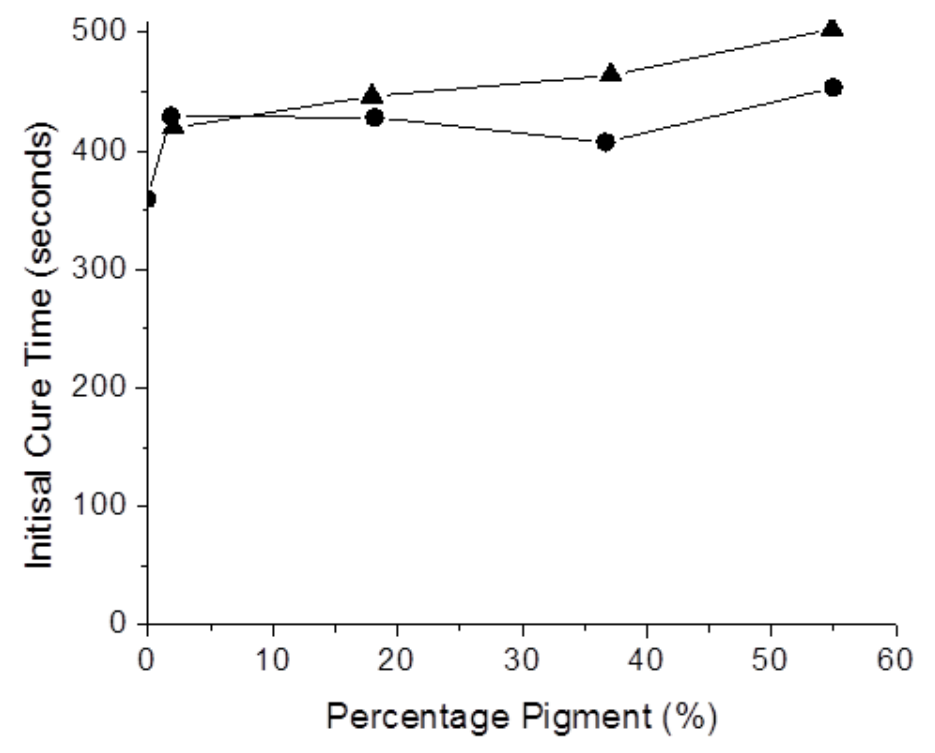

[A] 


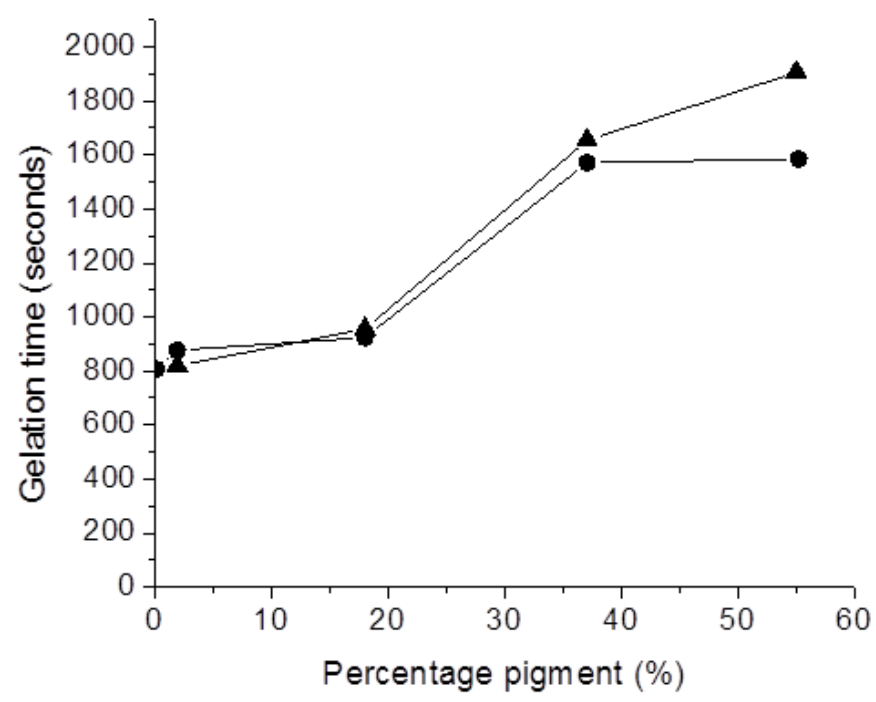

[B]

Figure (5) Effect of pigment loading on Initial Cure Time[A] and Gelation Time [B] with 4\% Modaflow. Key:-• - pigment 4B, $\boldsymbol{\Delta}$ - pigment 6B. Error bars are the size of the data points

The initial cure time is inhibited relative to the unpigmented material but at $4 \%$ Modaflow loading the relative differences between the $4 \mathrm{~b}$ and $6 \mathrm{~B}$ pigments are reduced, the $6 \mathrm{~B}$ still being inhibited more than the 4B. At 4\% Modaflow loading the differences between the two pigments is significantly reduced and it is only at the highest loading $60 \%$ that differences between $4 \mathrm{~B}$ and $6 \mathrm{~B}$ become evident.

The Modaflow appears to act in a similar manner to the wax and block the effect of specific surface sites on the cure process. The increase in the initial cure and gelation time reflect the inhibition effect of the pigment on the cure process. As the pigment level increases so the amount of resin to be cured decreases which should lead to faster cure times than for the pure resin. However increasing the filler level increases the thermal mass and reduces the cure exotherm leading to a slower cure process. The general upward trend in the initial cure and gelation times is therefore partly attributed to the increase in thermal mass effects on the cure process.

\section{Conclusion from the curometer study}


Modaflow has a small effect on the cure reaction of the polyester, assisting the initial melt and lowering the viscosity of the resin but this does not necessarily lead to a significant effect on the gelation times. The optimum Modaflow concentration appears to be $\sim 1.5 \%$. The dominant effect in terms of change in the initial cure and gelation times is change in the silica content of the pigment coating. A high silica content appears to retard the polymerization reaction. The observed retardation effects must be due to direct chemical interaction between the pigment and the components of the polyester curing system. Two main mechanisms for the retardation can be proposed:-

i) The surface rich in silica has the potential of adsorbing the reactive polyester end group and inhibiting the reaction by reducing the number available for reaction. Whilst this possibility can not be excluded the low surface area of the pigments c.a. $10 \mathrm{~m}^{2} \mathrm{~g}^{-1}$ would suggest that the effect should be quite small and is not totally consistent with the observations of inhibition observed.

ii) The polymerization process involves the opening of the epoxy ring on the TGIC which will then either react with itself- homo-polymerization or with the polyester. This process can be acid or base catalysed and hence sensitive to the surface chemistry. In addition to the possible effects of changing the alumina:silica ratio on the surface $\mathrm{pH}$, the nature of the organic treatment can have a possible influence. TEA can catalyse the ring opening process but may be adsorbed on the pigment surface depending on the alumina:silica content. Lewis bases (tertiary amines) and Lewis acids (e.g. boron trifluoride) are known to catalyse the epoxy ring opening process (31-33). The observed retardation of the cure process suggest that the surface sites are not catalysis the ring opening process. It would appear that the surface is adsorbing or otherwise nullifying the catalysts for the polymerization of the polyester. The cure process for a polyester cure is summarised in scheme (1). 


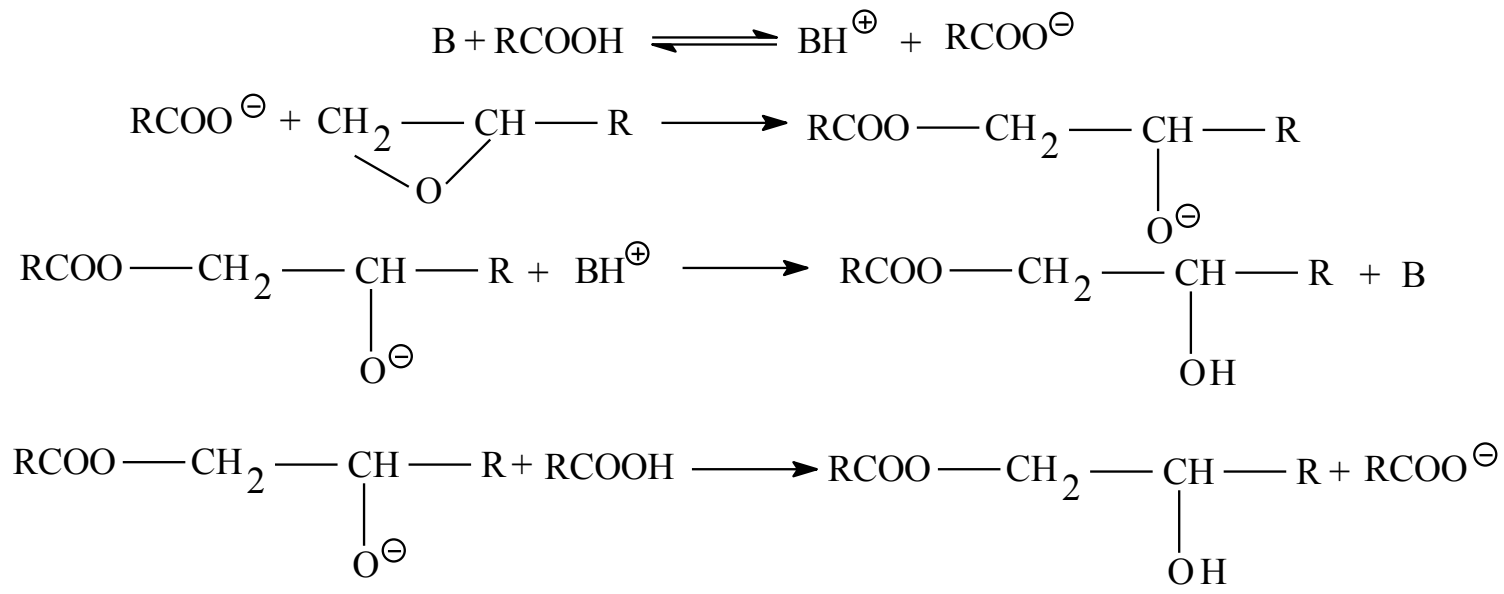

Scheme (1)

The Modaflow appear to be adsorbed, in part onto the pigment surface sites and hence effectively blocks their ability to interact with the catalyst. Pigment $4 \mathrm{~B}$ has a low silica level and has the least effect on cure, whereas 6B has a higher silica level and shows significant retardation effects on the cure process. The curometer data shows that the surface coating on the titanium dioxide surface has a significant effect on the cure of polyester coatings and the nature of effects can be influenced by the presence of zirconium in the pigment.

\section{Thermal Stimulated Discharge Spectroscopy -TSD}

The TSD method allows determination of the dynamic and electrical response of coatings $(30,34)$. A typical set of TSD traces for a cured polyester coating made at various stages of cure at $120^{\circ} \mathrm{C}$, are shown in figure (6). This coating does not contain pigment and post curing of the film causes the location of the peak to move, initially, to lower temperatures and then finally to higher temperatures. The peak is associated with the onset of motion in the matrix which assists discharge of trapped charges and is associated with the glass to rubber transition $\left[\mathrm{T}_{\mathrm{g}}\right]$. The shifts observed are consistent with the initial network formation creating an open structure which on densification leads to the observed increase in $\mathrm{T}_{\mathrm{g}}$. The start of a peak above $110^{\circ} \mathrm{C}$ is associated with space charge effects in the matrix. The space charge effects are a result of heterogeneity and the polymer work electrode work function inhibiting discharge of mobile charges. This peak is a reflection of the ability of the powder to retain a static charge. 


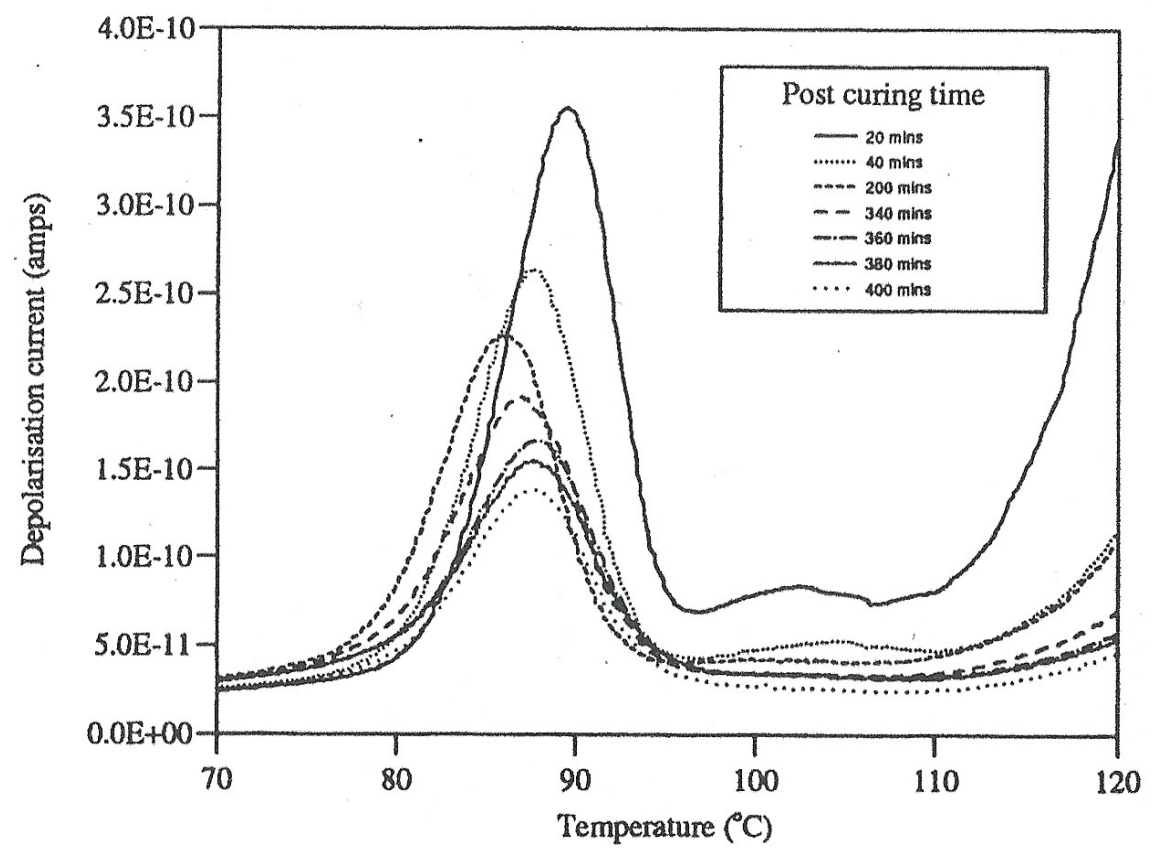

Figure (6) Effect of Post cure on the thermally Stimulated Depolarization traces for an unpigmented polyester coating

As cure proceeds, the space charge contribution decreases which reflects the formation of the crosslinked network inhibiting charge migration through the film. Usually post cure leads to an increase in the $T_{g}$, however in the case of the polyester this is not the case, the final $T_{g}$ being lower than the value at 300 minutes. The down ward shift of the $T_{g}$ peak on post cure is rather unusual, and implies that the glass transition temperature of the coating decreases on post cure and reflects relaxation of initially stresses formed in the matrix on post cure. The relaxation of the stresses in the matrix will be assisted by the presence of Modaflow and the final value of $\mathrm{T}_{\mathrm{g}}$ is $87^{\circ} \mathrm{C}$.

The addition of pigment 4B changes the observed behaviour, figure (7). 


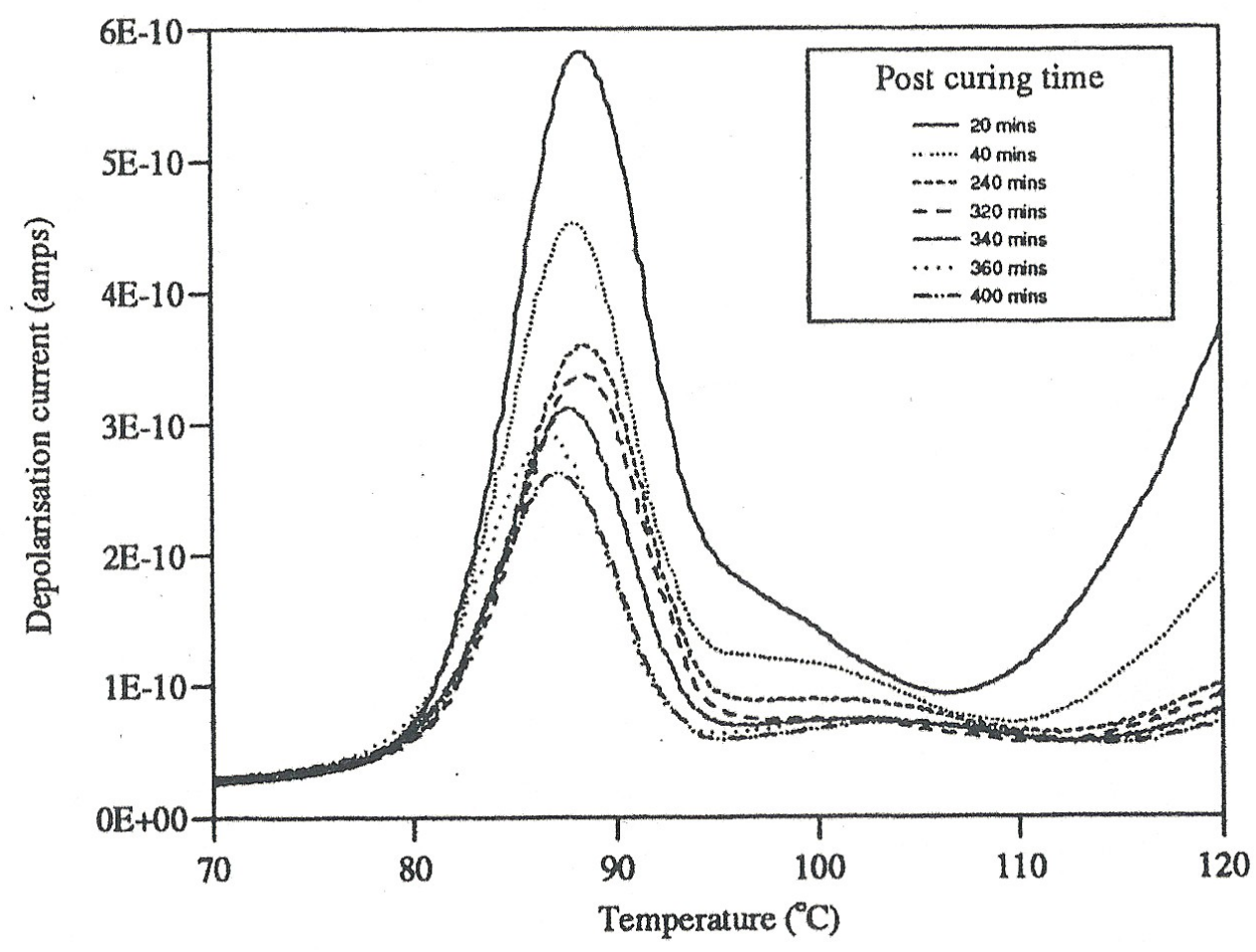

Figure (7) Effect of Post cure on the thermally Stimulated Depolarization traces for polyester coating with pigment 4B and Modaflow.

The shifts during the cure and post cure processes are much smaller implying that interaction of the resin with the pigment reduces the extent to which morphological changes are occurring in the resin phase. The final value of the $T_{g}$ is similar to that in the pure resin. Post cure reduces the amplitude of the space charge peak consistent with a reduction in mobility of the charges in the system. The final value of $T_{g}$ has a value of $88^{\circ} \mathrm{C}$. Parallel measurements without Modaflow being present gave values of $108^{\circ} \mathrm{C}$ indicating that it is aiding the structural changes within the curing matrix.

Cure of pigmented polyester with 6B and Modaflow, figure (8), shows a progressive downwards shift of the $T_{g}$ as the cure proceeds, however the final value of the $T_{g}$ is typically $92^{\circ} \mathrm{C}$. The differences observed may be a consequence of the pigments ability to influence the nature of the final resin matrix structure. To complement the TSD measurements DMTA studies were carried out on fully cured samples of the coating. 


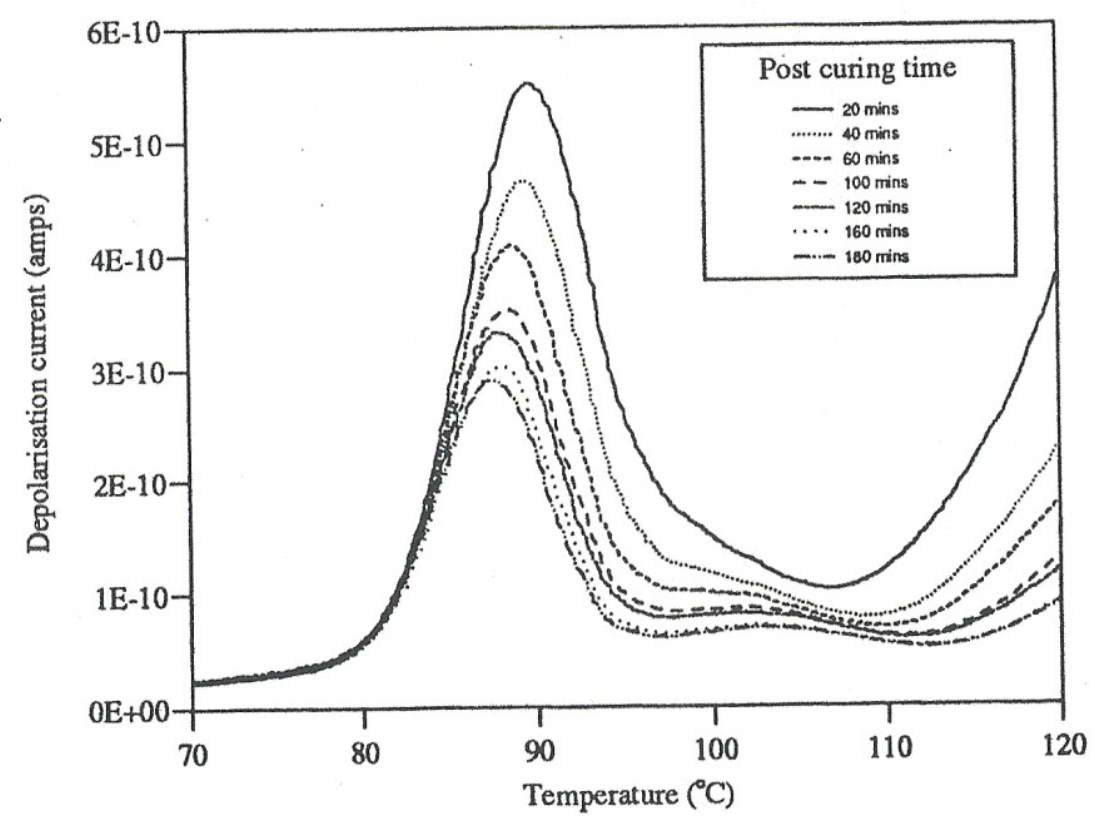

Figure (8) Effect of Post cure on the thermally Stimulated Depolarization traces for polyester coating with pigment $6 \mathrm{~B}$ and Modaflow.

\section{Dynamic Mechanical Thermal Analysis}

DMTA measurements were performed on the coatings and a typical trace is shown in figure (9). The traces obtained for all the coatings were very similar and confirmed the location of the $\mathrm{T}_{\mathrm{g}}$ process as being at $\sim 90^{\circ} \mathrm{C}$. Small differences were observed with change in the pigment and the level of Modaflow, the latter shifting the $\mathrm{T}_{\mathrm{g}}$ to lower temperatures. 


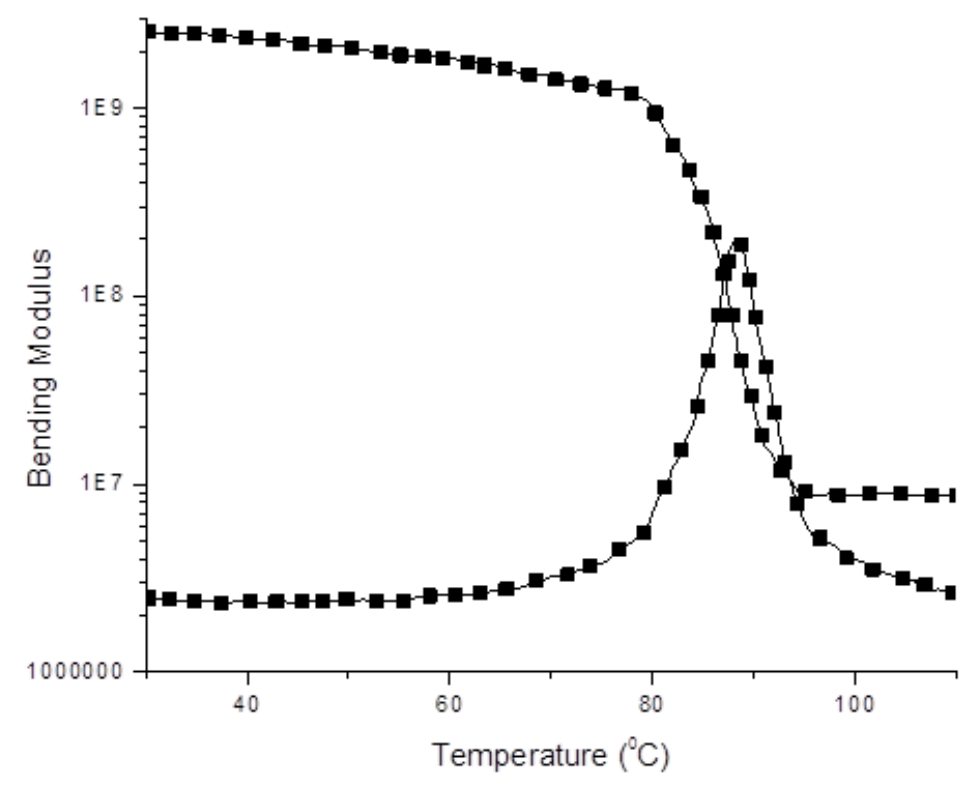

Figure (9) Dynamic Mechanical Thermal Analysis trace for a cured polyester coating. Key:- top trace is the bending modulus and the lower $\operatorname{trace} \tan \delta$.

\section{Conclusions}

The study indicates that the nature of the surface pacifying for titanium dioxide pigments is important when they are used with polyester curing systems. Studies using polyacrylic acid have shown that $\mathrm{TiO}_{2}$ adsorbs polymer on to its surface [36]. It is therefore reasonable to expect that the polyester will be able to be adsorbed by pigment and in the solid phase can play an important role in determining the distribution of pigment in the system [10, 37-38]. The effects of the surface coatings on the pigments behaviour dependent on the silica level in the coating and imply that there is an interaction between the surface and catalyst which inhibits its effectiveness in catalysing the cure reaction. The presence of zirconium appears also to have an effect on the cure behaviour possible through its influence on the nature of the surface layer created during the coating process.

\section{Acknowledgements}

One of us (AMcK) wishes to acknowledge support form the EPSRC and ICI / Huntsman in the form of a Case studentship. 


\section{References}

1) Edgerton T.A.; Parfitt, G.D.; Kang, Y; Wightman, J.P.; XPS Analysis of Uncoated and Silica-Coated Titanium-Dioxide Powders, Colloids and Surfaces (1983) 7 (4) 311323.

2) Egerton T.A.; King, C.J.; Influence of Light-Intensity on Photoactivity in $\mathrm{TiO}_{2}$ Pigmented Systems, Journal Oil \& Colour Chemists Association (1979) 62 (10) 386-391.

3) Montazer M., Moeshedi S., Nano photo scouring and nano photo bleaching of raw cellulosic fabric using nano $\mathrm{TiO} 2$ International Journal of Biological Macromolecules 50 (2012) 1018-1025.

4) Su X., Wu Q. L., Zhan X., Wu J., Wei S., Guo Z., Advanced titania nanostructures and composites for lithium ion battery, J Mater Sci (2012) 47:2519-2534

5) Al-Ahmed A., Mukhtar B., Hossain S., Zaidi S.M.J., Rahman S.U., Application of Titanium dioxide ( $\mathrm{TiO} 2)$ based photocatalytic nanomaterials in Solar and Hydrogen Energy: A Short Review Materials Science Forum Vol. 712 (2012) pp 25-47

6) Macwan D.P., N. Dave P.N., Chaturvedi S., A review on nano-TiO2 sol-gel type syntheses and its applications, J Mater Sci (2011) 46:3669-3686

7) Lang X., ,Chen X., Zhao J., Heterogeneous visible light photocatalysis for selective organic transformations: Chem. Rev. $201443473-485$

8) Froschl, T., Hormann, U., Kubiak, P., Kucerova G., Pfanzelt, M., Weiss C.K., Behm R.J., Husing,N., Kaiser U., Landfesterd K., Wohlfahrt-Mehrens M., High surface area crystalline titanium dioxide: potential and limits in electrochemical energy storage and catalysis Chem. Soc. Rev., 2012,41, 5313-5360

9) Croll S., DLVO theory applied to $\mathrm{TiO} 2$ pigments and other materials in latex paints Progress in Organic Coatings 44 (2002) 131-146

10) Farrokhpay S. A review of polymeric dispersant stabilisation of titania pigment, Advances in Colloid and Interface Science 151 (2009) 24-32

11) Croll S.G., Taylor C.A., Hydrated alumina surface treatment on a titanium dioxide pigment: Changes at acidic and basic pH. Journal of Colloid and Interface Science 314 (2007) 531-539

12) Braun J.H., Titanium dioxide--a review, Journal of Coatings Technology; May 1997; 69,868 
13) Juergen H. Braun J.H., Baidins A., Marganski R.E., $\mathrm{TiO}_{2}$ pigment technology: a review, Progress in Organic Coatings, 20 (1992) 105-138

14) Entwistle T; Gill S.J., Effect of Titanium -Dioxide Pigments on the Cure of Thermosetting Films, Journal Oil \& Colour Chemists Association (1986) 69 (2) 25-42.

15) Rusu, M.; Mindrila, P.C., The optimization of some white epoxy-polyester coating powders composition Materiale Plastice (2004) 41 (1) 29-35.

16) Johansson, L.S.; Losoi, T., Surface Characterization of Coated Powders - $\mathrm{Al}_{2} \mathrm{O}_{3}$ $\mathrm{SiO}_{2}$-Coated $\mathrm{TiO}_{2}$, Surface and Interface Analysis, (1991) 17 (5) 230-236.

17) Hanna, T. R., Predicting Paint Properties from TiO(2) Pigment Properties, J.C.T. Coatings Tech (2009) 6 (5) 26-31.

18) Wiseman T.J., Characterisation of Powder Surfaces, Chapter 4, Ed Parfitt G.D. and Sing K.S.W., Academic Press, New York (1976).

19) Johansson L.S., Static SIMS Studies of Coated $\mathrm{TiO}_{2}$ Pigments, Surface and Interface Analysis (1993) 20 (4) 304-308

20) Morterra C., Cerrato G., Visca M., Lenti D. M., Surface Characterization of some Ti0,-based Pigments, Part 3. - Coating of the Pigment, J. Mater. Chem.1992, 2(3), 341355

21) Mirabedinia,S.M. Kiamanesh A., The effect of micro and nano-sized particles on mechanical and adhesion properties of a clear polyester powder coating Progress in Organic Coatings 76 (2013) 1625-1632.

22) Vargha1 V., Vorster O., Finta Zs., Csuka G., TTT Analysis of a Powder Coating System based on Polyester Resin and Triglycidyl-Isocyanurate Part I. Gelation of Matrix and Powder, Journal of Thermal Analysis and Calorimetry, Vol. 83 (2006) 1, 199-206 23) Swaraj P., Surface Coatings; Science and Technology, Wiley Interscience, New York, Journal of Thermal Analysis and Calorimetry, Vol. 83 (2006) 1, 199-206

24) Kapilow L., Sammel R., Resins and Curing Agents for Thermosetting Powder Coatings, J. Coating Technology (1987) 59 (750) 39-4759

25) Misev T.A., Van der Linde R., Powder coatings technology: new developments at the turn of the century, Progress in Organic Coatings (1998) 4 (1-4) 160 - 168. 
26) de Boer J.H.; Lippens B.C.; Linsen, B.G.; Broekhof J.C.; Vandenhe A.; Osinga T.J.; T-Curve of Multimolecular $\mathrm{N}_{2}$-Adsorption, J. Colloid and Interface Science (166) 21 (4) $405-410$.

27) Affrosman S., Collins A., Hayward D., Trottier E., Pethrick R.A., Versatile Method of Characterizing Cure in Filled Reactive Polymer Systems, J. Oil \& Colour Chemists Association, (1989) 72 (11) 452-453.

28) Ingram S., Dennis H., Hunter I., Liggat J.J., McAdam C., Pethrick R.A., Schaschke C., Thomson D., Influence of clay type on exfoliation, cure and physical properties of in situ polymerised poly(methyl methacrylate) nanocomposites Polym Int (2008) 571118 1127

29) Van Turnhout J. in 'Electrets' - Topics in Applied Physics “Ed G.M.Sessler, Vol 33 (1980) Springler Verlag, Berlin.

30) R.A. Daly J.H., Hayward D., Pethrick R.A., Studies of Dielectric-Constant

Measurements and Tribo-Electric Charging of Pigmented Polymer Systems, J. Physics D - Applied Physics ( 1986) 19 (5) 885-896.

31) May C.A. 'Epoxy Resins: Chemistry and Technology', $2^{\text {nd }}$ Edition Marcel Dekker, New York (1980)

32) St Pierre L.E., Polyesters Part (1) Polyalkylene oxides and other Polyesters' Chapter 3 Ed Gaylord N.G. Interscience (1963)

33) Smith R.E., Larsen F.N. Long CV.L., Epoxy resin cure. I. Fluorine-19 NMR of boron trifluoride monoethylamine and fluoroboric acid, J.Applied Polymer Science 29 (1984) 3697- 3711 .

34) Shi Q-W., Huang W., Zhang Y., Zhang Y., Xu Y., Guo G., Curing of polyester powder coating modified with rutile nano-sized titanium dioxide studied by DSC and real-time FT-IR., J Therm Anal Calorim (2012) 108 1243-1249

35) Creswell R.A., Perlamn M.M., Thermal Currents from Corona Charged Mylar J. Applied Phys (1970) 41 2365-2375

36) Banash M.A, Croll S.G., A Quantitative study of polymeric dispersant adsorption onto oxide-coated titania pigmentsProgress in Organic Coatings 35 (1999) 37-44

37) Farrokhpay S., Morris G.A., Fornasiero D., Self P., Stabilisation of titania pigment particles with anionic polymeric dispersants, Powder Technology 202 (2010) 143-150

Peer-reviewed, accepted author manuscript of the following article: Affrossman, S., McKee, A. \& Pethrick, R. A. (2015). Effect of surface treatments of titanium dioxide pigments on the cure of polyester/triglycidyl isocyanurate powder coatings. Journal of Coatings Technology Research. 10.1007/s1 1998-015-9697-9 
38) Mirabedinia S.M., Kiamanesh A., The effect of micro and nano-sized particles on mechanical andadhesion properties of a clear polyester powder coating. Progress in Organic Coatings 76 (2013) 1625-1632 